BNL-66807

Holden, N.E. ${ }^{1}$, Hu, J-P. ${ }^{1}$, Greenberg, D.D. ${ }^{1}$, Reciniello, R.N. ${ }^{1}$, Farrell, K. ${ }^{2}$ and Greenwood, L.R. ${ }^{3}$

\title{
Radiation Dosimetry at the BNL High Flux Beam Reactor and Medical Research Reactor
}

Reference:Holden,N.E., Hu,J-P., Greenberg,D.D., Reciniello, R.N., Farrell,K. and Greenwood,L.R.,"Radiation Dosimetry at the BNL High Flux Beam Reactor and Medical Research Reactor,'Reactor Dosimetry,ASTM STP1398, John G. Williams, David W. Vehar, Frank H. Ruddy and David M. Gilliam, Eds., American Society for Testing and Materials, West Conshoken, PA,2000.

\begin{abstract}
Radiation dosimetry measurements have been performed over a period of many years at the High Flux Beam Reactor (HFBR) and the Medical Research Reactor (BMRR) at Brookhaven National Laboratory to provide information on the energy distribution of the neutron flux, neutron dose rates, gamma-ray fluxes and gamma-ray dose rates. The MCNP Particle Transport Code provided Monte Carlo results to compare with various dosimetry measurements performed at the experimental ports, at the treatment rooms and in the thimbles at both the HFBR and BMRR.
\end{abstract}

Keywords: HFBR, BMRR, neutron, gamma-ray, fluxes, dose rates, MCNP

\section{INTRODUCTION}

HFBR is a heavy water $\left(\mathrm{D}_{2} \mathrm{O}\right)$ cooled and moderated reactor, which was designed to operate at a power level of 40 mega-watts (MW). It was later upgraded to $60 \mathrm{MW}$ and it was last run at $30 \mathrm{MW}$ using a twenty-four hour, thirty day continuous operating cycle. The HFBR has 9 horizontal beam tubes, H-1 to H-9, which support up to 16 beam line experiments. These beam line experiments are used for neutron scattering research in solid state and nuclear physics, chemistry and biology. The HFBR also has 7 vertical thimbles, V10 to V-16, where samples are inserted for fast neutron and gamma-ray material damage studies, for medical radio-nuclide production and research and for neutron activation analysis

\footnotetext{
${ }^{1}$ Brookhaven National Laboratory

${ }^{2}$ Oak Ridge National Laboratory

${ }^{3}$ Pacific Northwest National Laboratory
} 
and thermal neutron damage studies. Thin foil dosimetry has been used at both the beam lines and the thimbles to characterize the energy distribution of the neutron flux. HFBR neutron fluxes at an in-core thimble, at a core edge thimble and at a $\mathrm{D}_{2} \mathrm{O}$ reflector thimble provided values in all energy ranges from thermal energies, $\mathrm{E}_{\mathrm{n}}<0.5 \mathrm{ev}$, up to the fast neutron energies $\left(E_{n}>0.11 \mathrm{Mev}\right)$. At the horizontal beam lines, neutron and gamma-ray dose rates have been measured with an Eberline ASP1 "rem-ball" \{a $0.229 \mathrm{~m}$ (nine inch) polyethylene sphere neutron sensitive instrument utilizing a $\mathrm{BF}_{3}$ detector[1] and with a small ion chamber with a $0.6 \mathrm{~cm}^{3}$ active volume.

BMRR is a light water $\left(\mathrm{H}_{2} \mathrm{O}\right)$ cooled and graphite moderated reactor, which is operated weekdays on demand at a power level of up to $3 \mathrm{MW}$ for both medical and biological research. Its primary use is for Boron Neutron Capture Therapy (BNCT) research and human patient clinical trials for brain tumors (glioblastoma multiforme). It has two treatment rooms, featuring a) an epithermal neutron beam (ENIF) and b) a thermal neutron beam (TNIF), horizontal tubes and a broad beam facility to irradiate large objects.

Dose rate and flux dosimetry measurements have been performed. Radiation dosimetry information was generated via use of activation foils, thermoluminescent dosimeters (TLDs), personnel monitoring badges featuring both ${ }^{6} \mathrm{LiF}$ and ${ }^{7} \mathrm{LiF}$ chips, an Eberline ASP1 "rem-ball" neutron sensitive instrument and an NRC ADM multi-purpose gamma sensitive instrument.

In both the ENIF and the TNIF, the neutron beam port is located $0.9144 \mathrm{~m}$ ( $3 \mathrm{feet}$ ) above the floor and almost in the center of the reactor wall. The last portion of radiation shielding in both beam ports are shields of bismuth. There are removable collimators mounted on the bismuth face to help to collimate the neutron beams emerging from the ports.

Neutron and Photon transport calculations were performed using the Monte Carlo program [2] MCNP-4B2. The energy dependent spatial distributions of prompt gamma-rays and prompt neutrons from thermal energies (0.01-0.4 ev) up to fast energies (0.1-10 Mev) were calculated in one run. ENDF/B-VI continuous neutron cross section data were used, including appropriate thermal neutron scattering function $S(\alpha, \beta)$ for $D_{2} O$ in the HFBR.

\section{HFBR THIMBLE DOSIMETRY}

Thermal, resonance and fast neutron activation reaction dosimeters have been exposed over the past thirty years in many vertical irradiation thimbles[3,4], in a) the reflector region, in b) the core edge region and in c) the in-core region.

The comparison of the neutron fluxes in the $\mathrm{D}_{2} \mathrm{O}$ reflector thimble $\mathrm{V}-10$ are shown in Table 1. The measurement was performed at a power level of $30 \mathrm{MW}$ with the dosimetry sample located at the bottom of the thimble, $0.18 \mathrm{~m}$ (7.1 inches) below the core mid-plane.

Table 1. Comparison of Neutron Fluxes in HFBR V-10 Thimble

\begin{tabular}{|l|c|c|c|}
\hline Neutron Energy & Experiment $\mathrm{n} / \mathrm{m}^{2} / \mathrm{s}$ & Calculation n/m²/s & Calculation/Expt. \\
\hline$<0.5 \mathrm{ev}$ & $1.57 \pm 0.09 \times 10^{18}$ & $2.61 \times 10^{18}$ & 1.66 \\
\hline $0.5 \mathrm{ev}-0.1 \mathrm{Mev}$ & $2.01 \pm 0.32 \times 10^{16}$ & $1.44 \times 10^{16}$ & 0.72 \\
\hline$>0.11 \mathrm{Mev}$ & $2.84 \pm 0.62 \times 10^{15}$ & $1.54 \times 10^{15}$ & 0.54 \\
\hline
\end{tabular}




\begin{tabular}{|l|l|l|l|}
\hline All Energies & $1.59 \pm 0.10 \times 10^{18}$ & $2.63 \times 10^{18}$ & 1.65 \\
\hline
\end{tabular}

The MCNP calculation was performed for a power level of $40 \mathrm{MW}$ at the same location and the neutron fluxes were renormalized to $30 \mathrm{MW}$ in Table 1 to allow a direct comparison.

In addition to this 1996 measurement, there had been a pair of $1 \mathrm{~mm}$ thick and $0.76 \mathrm{~mm}$ radius cobalt foils exposed in the V-10 facility [5] during 1966. The thermal neutron flux value $\left(2200 \mathrm{~m} / \mathrm{s}\right.$ value) of $1.46 \times 10^{18} \mathrm{n} / \mathrm{m}^{2} / \mathrm{s}$ at $30 \mathrm{MW}$ can be compared to the flux value of $1.57 \times 10^{18} \mathrm{n} / \mathrm{m}^{2} / \mathrm{s}$ in Table 1 . These fluxes measured thirty years apart are in good agreement.

The comparison of the neutron flux values in the core edge region thimble, $\mathrm{V}-14$, are shown in Table 2. Again the measurement was performed at a power level of $30 \mathrm{MW}$ with the dosimetry sample located at the bottom of the thimble, $0.155 \mathrm{~m}$ (6.1 inches) below the core mid-plane. The calculation was again renormalized from $40 \mathrm{MW}$ to $30 \mathrm{MW}$ to allow a direct comparison.

Table 2. Comparison of Neutron Fluxes in HFBR V-14 Thimble

\begin{tabular}{|l|c|c|c|}
\hline Neutron Energy & Experiment n/m²/s & Calculation n $/ \mathrm{m}^{2} / \mathrm{s}$ & Calculation/Expt. \\
\hline$<0.5 \mathrm{ev}$ & $4.96 \pm 0.50 \times 10^{18}$ & $6.34 \times 10^{18}$ & 1.28 \\
\hline $0.5 \mathrm{ev}-0.1 \mathrm{Mev}$ & $4.99 \pm 1.00 \times 10^{18}$ & $5.10 \times 10^{18}$ & 1.02 \\
\hline$>0.11 \mathrm{Mev}$ & $5.99 \pm 0.60 \times 10^{17}$ & $9.30 \times 10^{17}$ & 1.55 \\
\hline All Energies & $1.06 \pm 0.08 \times 10^{19}$ & $1.24 \times 10^{19}$ & 1.17 \\
\hline
\end{tabular}

The comparison of the neutron flux values in the in-core thimble V-15 are shown in Table 3. In this thimble, three different sets of measurements were made; the first measurement was made in 1976 at a power level of $40 \mathrm{MW}$ with the sample located $0.216 \mathrm{~m}$ (0.85 inches) below the core midplane; the second measurement was made in 1989 at a power level of 60 MW with the sample at the core midplane; the third and final measurement was made in 1996 at a power level of $30 \mathrm{MW}$ with the sample at the core midplane. The calculated values were again renormalized from $40 \mathrm{MW}$ to $30 \mathrm{MW}$. All three of these measurements are also normalized to $30 \mathrm{MW}$ in the Table to provide a direct comparison.

Table 3. Comparison of Neutron Fluxes in HFBR V-15 Thimble

\begin{tabular}{|l|c|c|c|c|c|}
\hline $\begin{array}{l}\text { Neutron } \\
\text { Energy }\end{array}$ & $\begin{array}{l}1996 \text { Expt. } \\
10^{18} \mathrm{n} / \mathrm{m}^{2} / \mathrm{s}\end{array}$ & $\begin{array}{l}1989 \mathrm{Expt} . \\
10^{18} \mathrm{n} / \mathrm{m}^{2} / \mathrm{s}\end{array}$ & $\begin{array}{l}1976 \mathrm{Expt} \\
10^{18} \mathrm{n} / \mathrm{m}^{2} / \mathrm{s}\end{array}$ & $\begin{array}{l}\text { Calculation } \\
10^{18} \mathrm{n} / \mathrm{m}^{2} / \mathrm{s}\end{array}$ & $\begin{array}{l}\text { Calculation } \\
/ 1996 \text { Expt. }\end{array}$ \\
\hline$<0.5 \mathrm{ev}$ & $1.23 \pm 0.10$ & $1.20 \pm 0.10$ & $1.16 \pm 0.13$ & 1.77 & 1.48 \\
\hline $\begin{array}{l}0.5 \mathrm{ev} \text { to } \\
0.1 \mathrm{Mev}\end{array}$ & $10.3 \pm 1.55$ & $11.0 \pm 1.64$ & $7.06 \pm 0.85$ & 13.7 & 1.28 \\
\hline$>0.11 \mathrm{Mev}$ & $2.64 \pm 0.26$ & $2.40 \pm 0.24$ & $4.38 \pm 0.53$ & 3.67 & 1.46 \\
\hline
\end{tabular}




\begin{tabular}{|l|l|l|l|l|l|}
\hline All Energies & $14.2 \pm 1.14$ & $14.6 \pm 1.17$ & $12.6 \pm 0.76$ & 19.1 & 1.35 \\
\hline
\end{tabular}

In addition to the above measurements, there was a Co-Al wire determination [3] of the thermal neutron flux in the $\mathrm{V}-11$ hydraulic tube thimble performed at $40 \mathrm{MW}$ power level in 1968 . The result renormalized to $30 \mathrm{MW}$ gives a $2200 \mathrm{~m} / \mathrm{s}$ flux of $8.2 \times 10^{17} \mathrm{n} / \mathrm{m}^{2} / \mathrm{s}$.

\section{HFBR BEAM LINE DOSIMETRY}

Various thermal, resonance and fast neutron reaction foils were irradiated at a number of horizontal beam lines $[5,6,7]$. At the $\mathrm{H}-1$ beam tube tip, the $30 \mathrm{MW} 2200 \mathrm{~m} / \mathrm{s}$ neutron flux was measured to be $4.6 \times 10^{18} \mathrm{n} / \mathrm{m}^{2} / \mathrm{s}$. At the sample position outside the reactor, after passing through both the beam tube collimator and a monochromator crystal and then being scattered at a particular angle, the thermal neutron flux drops to about $10^{11} \mathrm{n} / \mathrm{m}^{2} / \mathrm{s}$.

It is of interest to note that the $\mathrm{H}-1$ beam tip is located at a radial distance of $0.33 \mathrm{~m}(13$ inches) from the core center and an axial position $0.1524 \mathrm{~m}$ (6 inches) below the core midplane. The vertical thimble V-14 is located $0.287 \mathrm{~m}$ (11.3 inches) radially from the core center and the bottom of the thimble is $0.18 \mathrm{~m}$ (7.1 inches) below the core midplane. Since these beam tips are close to the same radial and axial location, the thermal neutron flux values should be about the same. The H-1 $2200 \mathrm{~m} / \mathrm{s}$ flux given above is $4.6 \times 10^{18} \mathrm{n} / \mathrm{m}^{2} / \mathrm{s}$ and the V-14 Table 2 thermal flux is $5.0 \times 10^{18} \mathrm{n} / \mathrm{m}^{2} / \mathrm{s}$. There is again excellent agreement from measurements, which had also been made thirty years apart.

At the H-8 beam line, neutron dose rates were measured using a "rem-ball" detector and the effective fast neutron dose rate, $\mathrm{E}_{\mathrm{n}} \approx 1 \mathrm{Mev}$, was $24 \mathrm{mSv} / \mathrm{h}(2.4 \mathrm{rem} / \mathrm{h})$. The thermal neutron dose rate was determined from the $2200 \mathrm{~m} / \mathrm{s}$ neutron flux measured at the sample position at the beam line using bare and cadmium covered gold foils. A cadmium ratio of about 650 indicated a highly thermalized beam and a $2200 \mathrm{~m} / \mathrm{s}$ flux of $1.5 \times 10^{11} \mathrm{n} / \mathrm{m}^{2} / \mathrm{s}$ gives a dose rate of about $0.55 \mathrm{~Sv} / \mathrm{h}(55 \mathrm{rem} / \mathrm{h})$. Gamma-ray dose rate measurements were taken with a $0.6 \mathrm{~cm}^{3}$ ion chamber and determined to be $0.22 \mathrm{~Gy} / \mathrm{h}(22 \mathrm{r} / \mathrm{h})$.

\section{BMRR EPITHERMAL TREATMENT ROOM}

In the beam center of the ENIF, there is a six inch thick collimator of polyethylene and $\mathrm{Li}_{2} \mathrm{CO}_{3}$ (93\% enriched in ${ }^{6} \mathrm{Li}, 45 \%$ by weight). There is a concave cavity in the collimator, which is $0.2 \mathrm{~m}$ in diameter on the reactor side, which tapers to $0.12 \mathrm{~m}$ on the room side. At the $0.12 \mathrm{~m}$ opening in the collimator, the $2200 \mathrm{~m} / \mathrm{s}$ neutron flux $\approx 3.4 \times 10^{11} \mathrm{n} / \mathrm{m}^{2} / \mathrm{s}$, the epithermal neutron flux $\approx 8.2 \times 10^{12} \mathrm{n} / \mathrm{m}^{2} / \mathrm{s}$ and the fast neutron flux $\approx 2.0 \times 10^{11} \mathrm{n} / \mathrm{m}^{2} / \mathrm{s}$. The MCNP calculations give a thermal neutron flux of $2.8 \times 10^{11} \mathrm{n} / \mathrm{m}^{2} / \mathrm{s}$, an epithermal neutron flux of $6.6 \times 10^{12} \mathrm{n} / \mathrm{m}^{2} / \mathrm{s}$ and a fast neutron flux of $1.7 \times 10^{11} \mathrm{n} / \mathrm{m}^{2} / \mathrm{s}$.

In the ENIF, experimental comparisons have been made with 1) BNCT patients in place in front of the collimator, with 2) a tissue equivalent head phantom in place to mock up the patient's head position and with 3) the room empty in order to study the impact of the patient on the background flux and dose rate values.

Neutron and gamma-ray dose rates were measured using TLD personnel monitoring badges with ${ }^{6} \mathrm{LiF}$ and ${ }^{7} \mathrm{LiF}$ chips. The results are listed in Table 4 . The neutron dose rate at a distance of $0.3 \mathrm{~m}$ from the opening in the collimator was measured with the Eberline ASP1 
"rem-ball" to be $1 \mathrm{~Sv} / \mathrm{h}(100 \mathrm{Rem} / \mathrm{h})$. At the same time, the NRC ADM multi-purpose gamma sensitive instrument was used to measure the gamma-ray dose rate at $0.3 \mathrm{~m}$ from the opening of the collimator to be $1 \mathrm{~Gy} / \mathrm{h}(100 \mathrm{R} / \mathrm{h})$. These values can be compared to the values for the neutron and gamma-ray dose rates of $2.66 \mathrm{~Sv} / \mathrm{h}(266 \mathrm{Rem} / \mathrm{h})$ and $1.38 \mathrm{~Gy} / \mathrm{h}(138 \mathrm{R} / \mathrm{h})$ from Table 4. The values from Table 4 were measured at the collimator face rather than $0.3 \mathrm{~m}$ away and should be larger due to the geometric factor, which may have a $1 / \mathrm{r}$ or a $1 / \mathrm{r}^{2}$ dependence. This can be seen to be indeed the case.

Table 4. Epithermal Room Neutron and Gamma-ray Dose Rates

\begin{tabular}{|c|c|c|c|c|c|c|}
\hline $\begin{array}{l}\text { Location } \\
\text { in Room }\end{array}$ & $\begin{array}{l}\text { Empty } \\
\text { Room }\end{array}$ & $\begin{array}{l}\text { Empty } \\
\text { Room }\end{array}$ & $\begin{array}{l}\text { Phantom } \\
\text { in Place }\end{array}$ & $\begin{array}{l}\text { Phantom } \\
\text { in Place }\end{array}$ & $\begin{array}{l}\text { Patient in } \\
\text { Place }\end{array}$ & $\begin{array}{l}\text { Patient in } \\
\text { Place }\end{array}$ \\
\hline & $\mathrm{N} \mathrm{Sv/h}$ & $\gamma \mathrm{Gy} / \mathrm{h}$ & N Sv/h & $\gamma \mathrm{Gy} / \mathrm{h}$ & $\mathrm{N} \mathrm{Sv/h}$ & $\gamma \mathrm{Gy} / \mathrm{h}$ \\
\hline Door & 0.21 & 0.015 & 0.13 & 0.008 & 0.14 & 0.013 \\
\hline $\begin{array}{c}\text { North } \\
\text { Window }\end{array}$ & 0.32 & 0.032 & 0.19 & 0.025 & 0.18 & 0.037 \\
\hline $\begin{array}{c}\text { South } \\
\text { Window }\end{array}$ & 0.2 & 0.017 & 0.11 & 0.009 & ---- & ---- \\
\hline $\begin{array}{l}0.9144 \mathrm{~m} \\
(3 \mathrm{ft}) \text { high } \\
\text { Opp.Wall }\end{array}$ & 0.45 & 0.055 & 0.13 & 0.032 & 0.13 & 0.047 \\
\hline $\begin{array}{l}2.438 \mathrm{~m} \\
(8 \mathrm{ft}) \text { high } \\
\text { Opp.Wall }\end{array}$ & 0.41 & 0.041 & 0.15 & 0.032 & 0.15 & 0.04 \\
\hline $\begin{array}{l}0.6096 \mathrm{~m} \\
\text { (2ft) right } \\
30^{\prime} \text { Clock }\end{array}$ & 0.35 & 0.048 & 0.29 & 0.048 & 0.52 & 0.068 \\
\hline $\begin{array}{l}0.6096 \mathrm{~m} \\
\text { (2ft)down } \\
60^{\prime} \text { Clock }\end{array}$ & 0.45 & 0.045 & 0.28 & 0.03 & 0.65 & 0.085 \\
\hline $\begin{array}{l}0.6096 \mathrm{~m} \\
(2 \mathrm{ft}) \text { left } \\
\text { 90'Clock }\end{array}$ & 0.32 & 0.064 & 0.24 & 0.051 & 0.27 & 0.094 \\
\hline $\begin{array}{l}0.6096 \mathrm{~m} \\
\text { (2ft)up, } 12 \\
\text { O'Clock }\end{array}$ & 0.26 & 0.15 & 0.23 & 0.23 & 0.3 & 0.24 \\
\hline
\end{tabular}




\begin{tabular}{|l|l|l|l|l|l|l|}
\hline $\begin{array}{l}1.219 \mathrm{~m} \\
\left(\begin{array}{l}\mathrm{ft}) \text { right } \\
\text { 3O'Clock }\end{array}\right.\end{array}$ & 0.29 & 0.025 & -- & --- & 0.14 & 0.078 \\
\hline Collimat. & 2.66 & 1.38 & & & & \\
\hline
\end{tabular}

From Table 4, it can be seen that the neutron and gamma-ray dose rates fall off rapidly as you move away from the center of the beam. For the empty room, there is a reduction in the neutron dose rate at the reactor face by a factor of five to ten in all directions (3 o' clock, 6 o'clock, 9 o'clock and 12 o'clock) at a distance of $0.6096 \mathrm{~m}$ from the beam center, compared to the collimator center value. There is a similar reduction of ten to thirty in the gamma-ray dose rate. For the area above the collimator, there appears to be much less gamma-ray shielding, resulting in a much larger gamma-ray dose rate under all conditions.

By comparing the data with the patient in place to the data for the empty room, there is obviously neutron scattering back from the patient to the face of the reactor. However, the scattering of the gamma radiation back to the reactor face is much larger. Although there is a significant reduction in the neutron dose rate at the $0.9144 \mathrm{~m}$ beam center position on the wall opposite the patient, there appears to be much less change in the gamma-ray dose rate. This would indicate that there is much more absorption of neutrons than gamma-radiation by the patient, which is of course, the preferred situation. It might be noted that the head phantom absorbs more gamma radiation than do the actual patients being exposed.

\section{BMRR THERMAL TREATMENT ROOM}

In the TNIF, there is also a removable collimator mounted on the bismuth face of the reactor wall. It is also made of a mixture of polyethylene and $\mathrm{Li}_{2} \mathrm{CO}_{3}\left(\approx 93 \%\right.$ enriched in ${ }^{6} \mathrm{Li}$, which is $45 \%$ by weight). This collimator is $0.102 \mathrm{~m}$ thick with a similar conical cavity, which is $0.12 \mathrm{~m}$ in diameter on the reactor core side and which tapers to $0.02 \mathrm{~m}$ on the side facing the shielded room. At the $0.02 \mathrm{~m}$ opening in the collimator face, the $2200 \mathrm{~m} / \mathrm{s}$ neutron flux $\approx 1.6 \times 10^{14} \mathrm{n} / \mathrm{m}^{2} / \mathrm{s}$, the epithermal neutron flux $\approx 1 \times 10^{13} \mathrm{n} / \mathrm{m}^{2} / \mathrm{s}$ and the fast neutron flux $\approx$ $4 \times 10^{12} \mathrm{n} / \mathrm{m}^{2} / \mathrm{s}$.

The MCNP calculations give neutron flux values at the opening in the collimator of a $2200 \mathrm{~m} / \mathrm{s}$ value $=1.6 \times 10^{14} \mathrm{n} / \mathrm{m}^{2} / \mathrm{s}$, an epithermal value $=1.4 \times 10^{13} \mathrm{n} / \mathrm{m}^{2} / \mathrm{s}$ and a fast value $=$ $4.3 \times 10^{12} \mathrm{n} / \mathrm{m}^{2} / \mathrm{s}$.

Neutron and gamma-ray dose rates measured in the thermal neutron irradiation facility (TNIF) are listed in Table 5, where measurements have been made in the center of the beam, and at various positions inside of and outside of the entrance door, the viewing window, the back wall of the TNIF and the back wall of the enclosure.

In the TNIF, there is a large polyethylene enclosure built around the beam port exit, where the neutron beam leaves the reactor face and the collimator. The neutron and gamma-ray dose rate values in Table 5, provide an indication of the effectiveness of the radiation shielding of this polyethylene enclosure, the shielding viewing window, the entrance door and the back wall of the treatment room for reducing the neutron and gamma-ray dose rates. In general, the attenuation of both the neutrons and the gamma-rays is at least one order of magnitude and in the case of the viewing window for neutrons, three orders of magnitude. 
In the case of the polyethylene enclosure, the attenuation for gamma-rays is only a factor of three.

Table 5. Thermal Room Neutron and Gamma-ray Dose Rates

\begin{tabular}{|l|c|c|}
\hline Location in Room & $\begin{array}{c}\text { Neutron Dose Rate } \\
(\mathrm{Sv} / \mathrm{h})\end{array}$ & $\begin{array}{c}\text { Gamma-ray Dose Rate } \\
(\mathrm{Gy} / \mathrm{h})\end{array}$ \\
\hline Door, Internal & 0.00054 & 0.00096 \\
\hline Door, External & 0.00006 & ------ \\
\hline Window, Internal & 0.0647 & 0.018 \\
\hline Window, External & 0.00006 & 0.0006 \\
\hline Collimator Face & 300. & 20. \\
\hline Collimator at 30 cm & 60. & 4. \\
\hline Backwall, Internal & 0.052 & 0.096 \\
\hline Backwall, External & 0.0022 & 0.0036 \\
\hline Enclosure, Internal & 2.21 & 1.44 \\
\hline Enclosure, External & 0.115 & 0.535 \\
\hline
\end{tabular}

\section{OTHER DATA}

The thermal and epithermal neutron flux values have been measured in the pneumatic $\left(\mathrm{P}_{\mathrm{n}}\right)$ tube of the BMRR, in which samples can be charged into the reactor adjacent to the core. The measured flux values are $\approx 9.6 \times 10^{16} \mathrm{n} / \mathrm{m}^{2} / \mathrm{s}$ and $\approx 2.0 \times 10^{16} \mathrm{n} / \mathrm{m}^{2} / \mathrm{s}$, while the calculated values are $5.4 \times 10^{16} \mathrm{n} / \mathrm{m}^{2} / \mathrm{s}$ and $3.4 \times 10^{16} \mathrm{n} / \mathrm{m}^{2} / \mathrm{s}$, respectively. For the radial tube, which is used to extract neutrons from the reactor in order to test for levels of boron in blood samples using neutron activation anaylsis, the $2200 \mathrm{~m} / \mathrm{s}$ neutron flux $\approx 2.5 \times 10^{11} \mathrm{n} / \mathrm{m}^{2} / \mathrm{s}$ and the epithermal neutron flux $\approx 1.3 \times 10^{10} \mathrm{n} / \mathrm{m}^{2} / \mathrm{s}$. The only calculated values at the radial tube have been performed for a bare tube with no collimator in the tube. These values will overestimate the neutron flux values. They are $3.0 \times 10^{12} \mathrm{n} / \mathrm{m}^{2} / \mathrm{s}$ and $1.3 \times 10^{13} \mathrm{n} / \mathrm{m}^{2} / \mathrm{s}$, respectively.

\section{DISCUSSION AND CONCLUSIONS}

The MCNP calculations which have been performed for the HFBR vertical thimbles used a fresh core of 28 new fuel elements, for which the critical control rod positions were 
determined $\left(\mathrm{k}_{\mathrm{eff}}=1\right)$. Generally, the samples were irradiated in an equilibrium core, where only one set of seven fuel elements is new. The other twenty-one elements have been fissioning for up to three 30 day fuel cycles. Since the control rods are usually out of the core at the end of the fuel cycle when most of these measurements were made, the active neutron source volume ratio in these two cases is 0.80 .

The MCNP calculations for the radial tube in the BMRR was calculated for the geometry of the reactor and the beam tube but the tube was empty. In the actual measurement, the beam tube has a steel collimator inserted but for which no details are available, so the calculations are much too large. Although the estimated uncertainties in the MCNP calculations are on the order of $5 \%$ to $10 \%$, this is strictly an estimate of the statistical uncertainties and no estimate of any systematic uncertainties has yet been made.

In the ENIF treatment room, where the BNCT patients are treated, the flux and dose rates are concentrated in the center of the beam and the patient absorbs neutrons rather than gamma radiation as was noted above.

In the TNIF treatment room, the shielding effectiveness of the treatment room walls, entrance door and viewing window has been determined to be a factor of twenty-five or more for both neutrons and gamma-rays.

\section{ACKNOWLEDGEMENTS}

The assistance of Dr Eugene Weinstock in the preparation of this paper is noted. Gene gratuitously provided details on his early measurement data at the HFBR.

This research was supported in part by the US Department of Energy under the contracts DE-AC02-98CH10886, DE-AC05-84OR21400 and DE-AC06-76RL01830.

\section{REFERENCES}

1. D. E. Hankins, "The Substitution of $\mathrm{a} \mathrm{BF}_{3}$ Probe for the LiI Crystal in Neutron remMeters", Health Physics, 14 (1968).pp518-520.

2. MCNP-4B2 Monte Carlo N-Particle Transport Code System (CCC-660), contributed by Los Alamos National Laboratory, January 29, 1997, distributed by the Oak Ridge Radiation Safety Information Computation Center.

3. E. Weinstock, private communication, Flux in V-11 Facility of HFBR (May 5, 1968).

4. L. R. Greenwood and R. T. Ratner, private communication, Neutron Dosimetry and Radiation Damage Calculation for HFBR (1997).

5. E. Weinstock and W. Tunney, private communication, Beam Quality Measurements on HFBR with 2" 2 2" Collimator (April 28, 1966).

6. E. Weinstock and J. Conant, private communication, Beam Quality Measurements on HFBR with 3', 10' and 30' collimators (September 16, 1966).

7. S. Sengupta, G. R. Holeman, H. F. Kahnhauser, R. N. Reciniello and N. E. Holden, "Personnel Dosimeter Calibration with Thermal Neutrons at the BNL High Flux Beam Reactor", Health Physics, 76 (1999).p S114. 